\title{
A 22q11.2 amplification in the region encoding microRNA-650 correlates with the epithelial to mesenchymal transition in breast cancer primary cultures of Mexican patients
}

\author{
M. LANGO-CHAVARRÍA ${ }^{1 *}$, G.K. CHIMAL-RAMÍREZ ${ }^{1 *}$, M.E. RUIZ-TACHIQUÍN ${ }^{2}$, \\ N.A. ESPINOZA-SÁNCHEZ ${ }^{1,3}$, M.C. SUÁREZ-ARRIAGA ${ }^{1,2,4}$ and E.M. FUENTES-PANANÁ ${ }^{1}$
}

${ }^{1}$ Research Unit on Virology and Cancer, Children's Hospital of Mexico 'Federico Gómez';

${ }^{2}$ Medical Research Unit on Human Genetics, Pediatric Hospital, Mexican Institute of Social Security XXI Century, Del. Cuauhtemoc, C.P. 06720 Mexico City, Mexico; ${ }^{3}$ Ph.D. Program in Biomedical Sciences, National Autonomous University of Mexico (UNAM), C.P. 04510 Mexico City, Mexico; ${ }^{4}$ M.Sc. Program in Microbiology, National School of Biological Sciences (ENCB), National Polytechnic Institute (IPN), C.P. 07738 Mexico City, Mexico

Received November 23, 2016; Accepted December 29, 2016

DOI: $10.3892 /$ ijo.2017.3842

\begin{abstract}
Breast cancer ranks first in incidence and mortality in working age women. Cancer initiation and progression relies on accumulation of genetic and epigenetic aberrations that alter cellular processes, among them, epithelial to mesenchymal transition (EMT) denotes particularly aggressive neoplasias given its capacity to invade and metastasize. Several microRNAs (miRNA) have been found able to regulate gene expression at the core of EMT. In this study, the Affymetrix CytoScan HD array was used to analyze three different primary tumor cell isolates from Mexican breast cancer patients. We found an amplification in band 22q11.2 shared by the three samples, in the region that encodes miRNA-650. Overexpression of this miRNA has been associated with downregulation of tumor suppressors ING4 and NDRG2, which have been implicated in cancer progression. Using the Pathway Linker platform the ING4 and NDRG2 interaction networks showed a significant association with signaling pathways commonly deregulated in cancer. Also, several studies support their participation in the EMT. Supporting the latter, we found that the three primary isolates were E-cadherin negative, vimentin positive, presented a cancer stem cell-like phenotype $\mathrm{CD} 44^{+} \mathrm{CD} 24^{-/ \text {low }}$ and were invasive in Transwell invasion assays. This evidence suggests that the gain of region
\end{abstract}

Correspondence to: Dr E.M. Fuentes-Pananá, Research Unit on Virology and Cancer, Children's Hospital of Mexico 'Federico Gómez', Dr. Márquez No. 162, Col. Doctores, Del. Cuauhtémoc, C.P. 06720 Mexico City, Mexico

E-mail: empanana@yahoo.com; ezequiel.fuentes@alumni.bcm.edu

*Contributed equally

Key words: breast cancer, 22q11.2 gene amplification, miR-650, ING4 and NDRG2 tumor suppressors, EMT and stemness
$22 \mathrm{q} 11.2$ contributes to trigger EMT. This is the first evidence linking miR-650 and breast cancer.

\section{Introduction}

Cancer is one of the most important challenges of human health today. Breast cancer $(\mathrm{BrC})$ is the most common malignancy in women with more than 500,000 deaths globally per year (1). Despite advances in diagnosis and treatment, most cases are still diagnosed at advanced stages, particularly in developing countries in which more than $60 \%$ of the fatalities occur (2). Genetic modifications in tumor suppressor genes and proto-oncogenes, together with epigenetic changes in DNA methylation, histone modifications and altered miRNA expression drive cancer evolution from a pre-malignant cell to a highly aggressive cancer cell $(3,4)$.

In aggressive tumors, cells acquire the ability to detach from neighboring cells, migrate and invade the surrounding tissue, access the blood or lymphatic vessels and colonize distant organs (5-7). These processes of invasion and metastasis are facilitated by epithelial to mesenchymal transition (EMT). During EMT tumor cells undergo a transcriptional re-programing, losing expression of epithelial genes, such as adhesion molecules that sustain cell to cell contacts, and instead express mesenchymal genes (8). Invasive cells are characterized by lack of expression of E-cadherin and gain of expression of vimentin and $\mathrm{N}$-cadherin, which are commonly used to identify EMT cells. EMT cells also switch from a cobblestone- to spindle (fibroblast-like) morphology. Expression of EMT markers often correlates with expression of a stem-like phenotype (for instance $\left.\mathrm{CD} 44^{+} \mathrm{CD} 24^{- \text {llow }}\right)(9-11)$. Therefore, it is thought that EMT is a mechanism that also facilitates stemness (12-14).

miRNAs are evolutionarily conserved noncoding RNA molecules that regulate gene expression. Today, more than 1800 miRNAs have been shown to regulate cellular processes such as cell differentiation, cell cycle and cell death, and thus their abnormal function also impacts human diseases. In cancer, 
different miRNAs have been classified as tumor suppressors when they regulate the expression of cellular oncogenes and as oncomiRs when they target tumor suppressor genes (15). For instance, recent studies have shown that miRNAs are important regulators of EMT (16). In the mammary gland the miR-200 family maintains the epithelial program by downregulating expression of ZEB1 and ZEB2, the master transcriptional activators of the EMT program (17). ZEB1 and ZEB2 are also transcriptional repressors of $C D H 1$, the gene that encodes E-cadherin $(18,19)$. On the other hand, the miR-221 family is frequently expressed in poorly differentiated aggressive breast tumors with EMT characteristics (20). miR-650 is a novel oncomiR also implicated in EMT. miR-650 is often expressed in prostate, colorectal, hepatocellular, skin and gastric cancers (21-25), with evidence that it targets tumor suppressors ING4 and NDRG2 $(23,26-28)$. ING4 and NDRG2 expression is often lost in cancer and different lines of evidence support their participation in EMT (29-33).

In this study, we examined the chromosomal abnormalities of three primary cultures isolated from Mexican patients with BrC using the microarray CytoScan HD and Chromosome Analysis Suite 3.0 software (Affymetrix, Santa Clara, CA, USA). We found a common genetic lesion in the three samples, an amplification of band q11.2 in chromosome 22, in the region that encodes miR-650. We also found that the three primary isolates were negative to E-cadherin, positive to vimentin and to the stem cell marker CD44, and were invasive in Transwell migration assays, supporting their acquisition of EMT-related properties.

\section{Materials and methods}

Patient description and ethics statement. Patient samples were obtained from the tissue bank of the Unidad de Investigación en Virología y Cáncer, Hospital Infantil de México Federico Gómez. All patients included in the study signed an informed consent to participate. The study was approved by the Scientific, Ethics and Biosafety Institutional Review Boards of the participating hospitals. Patients included were diagnosed with invasive ductal carcinoma, histological grade 2 and clinical stage II, with no previous neoadjuvant therapy before tissue resection. Patients were all female aged 42, 64 and 55 years.

Tissue processing for primary cell culture isolation. Tumor tissues were rinsed with sterile PBS and mechanically disaggregated with a scalpel in 1-2-mm fragments, which were subsequently digested for $2 \mathrm{~h}$ at room temperature (RT) with a mixture of $1 \mathrm{mg} / \mathrm{ml}$ collagenase type I (C0130-100 MG, Sigma, St. Louis, MO, USA) and $100 \mathrm{U} / \mathrm{ml}$ hyaluronidase (H3506-100MG, Sigma) in DMEM/F12 (Dulbecco's modified Eagle's medium/Nutrient Mixture F-12) (11039-047, Gibco-Invitrogen Cell Culture, Carlsbad, CA, USA) supplemented with $100 \mathrm{U} / \mathrm{ml}$ penicillin and $100 \mu \mathrm{g} / \mathrm{ml}$ streptomycin (15140-122, Gibco-Invitrogen Cell Culture) in constant stirring. The resulting suspension was filtered through a wide pore membrane and a $100 \mu \mathrm{m}$ membrane. The cells were pelleted and washed twice with sterile PBS and plated in an enriched medium for epithelial cells [DMEM/F12 supplemented with 5\% horse serum (26050088, Gibco, Auckland, New Zealand), $10 \mathrm{ng} / \mathrm{ml}$ cholera toxin (C8052), $0.5 \mu \mathrm{g} / \mathrm{ml}$ hydrocortisone (H0888), $5 \mu \mathrm{g} / \mathrm{ml}$ insulin (91077C), all from
Sigma Chemical Co. (St. Louis, MO, USA), $5 \mathrm{ng} / \mathrm{ml}$ epidermal growth factor (EGF) (AF-100-15, PeproTech, Rocky Hill, NJ, USA)] and $1 \%$ penicillin/streptomycin $100 \mathrm{X}$, and then incubated at $37^{\circ} \mathrm{C}$ in a $5 \% \mathrm{CO}_{2}$ atmosphere. To assure the epithelial origin of the isolated cells, three epithelial markers were tested by immunocytochemistry: mouse monoclonal anti-human anti-PanCytokeratin (CM011A, clone: AE1/AE3, Biocare Medical, Concord, CA, USA), mouse monoclonal anti-human anti-mucin 1 (MUC-1) [Epithelial Membrane Antigen (EMA) (559774, clone: Mc-5, Biocare Medical)], and mouse monoclonal anti-human anti-epithelial cell adhesion molecule (EpCAM) (ab20160, clone: AUA1, Biocare Medical) all in a working dilution 1:50. The epithelial cell isolates were named as UIVC-IDC- $6,-9$ and -10 .

Analysis of the primary cultures using the microarray CytoScan $H D$ and Chromosome Analysis Suite 3.0 software. Total DNA from an early passage $(<6)$ of the three primary $\mathrm{BrC}$ cultures was isolated using the QIAamp ${ }^{\circledR}$ DNA Micro kit (56304, Qiagen, Gaithersburg, MD, USA) according to the manufacturer's protocol. To verify the quality of DNA, the endogenous $\beta$-actin gene was amplified by PCR. The Affymetrix CytoScan HD array (901835, Affymetrix) was used to evaluate copy number and loss of heterozygosity ( $\mathrm{LOH})$. This array contains more than 2.6 million copy number markers, of which 750,000 are 'genotype-able' single nucleotide polymorphisms (SNPs) and 1.9 million are non-polymorphic probes. Chromosome Analysis Suite (ChAS) software v3.0 (Affymetrix) was used for data analysis; for gains and losses we considered a minimum length of 100,000 base pairs (bp), and for $\mathrm{LOH}$ a minimum length of $3 \mathrm{Mbp}$. We compared all resulting alterations in the three $\mathrm{BrC}$ primary samples against female and male non-cancer control array data. Data from 1038 phenotypically healthy individuals (Affymetrix) and from Database of Genomic Variants were used as reference. Alterations found only in $<1 \%$ (rare) or never described (new rare) of the reference population were considered.

Bioinformatic analysis. The data were first classified as gains, losses and $\mathrm{LOH}$ for each individual sample, and then as shared by more than one sample. An amplification in the region $22 q 11.2$ was found common to all the primary cultures, harboring the gene for miR-650. We searched for interaction networks between miR-650 and cancer, and more specifically with BrC, using the Cytoscape ${ }^{\circledR}$ Analysis platform (http://www. cytoscape.org). The target genes of miR-650 were confirmed with three databases: Target $\operatorname{Scan}^{\circledR}$ (http://www.targetscan. org/), miRDB (http://mirdb.org/miRDB/) and microRNA. org (http://www.microrna.org/). We searched for the proteins encoded by the target genes identified. The online platform Pathway Linker ${ }^{\circledR}$ (http://pathwaylinker.org) was used to determine protein-protein interaction networks; this platform uses three different databases: KEGG (Kyoto Encyclopedia of Genes and Genomes), Reactome and SignaLink database.

Immunofluorescence assay. Cells $\left(3 \times 10^{4}\right)$ of each of the primary isolates were seeded on coverslips for $24 \mathrm{~h}$, fixed with paraformaldehyde $4 \%$ for $10 \mathrm{~min}$, and permeabilized with $0.2 \%$ Triton X-100 in PBS for 20 min (both from Sigma-Aldrich Co., St. Louis, MO, USA, ref. P6148-500G and T8787-100 ML, respectively). Cells were blocked with 
A

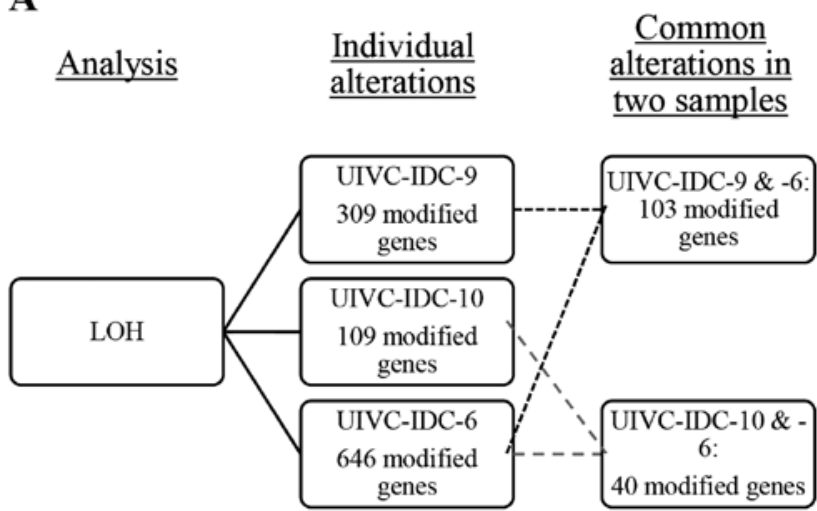

B

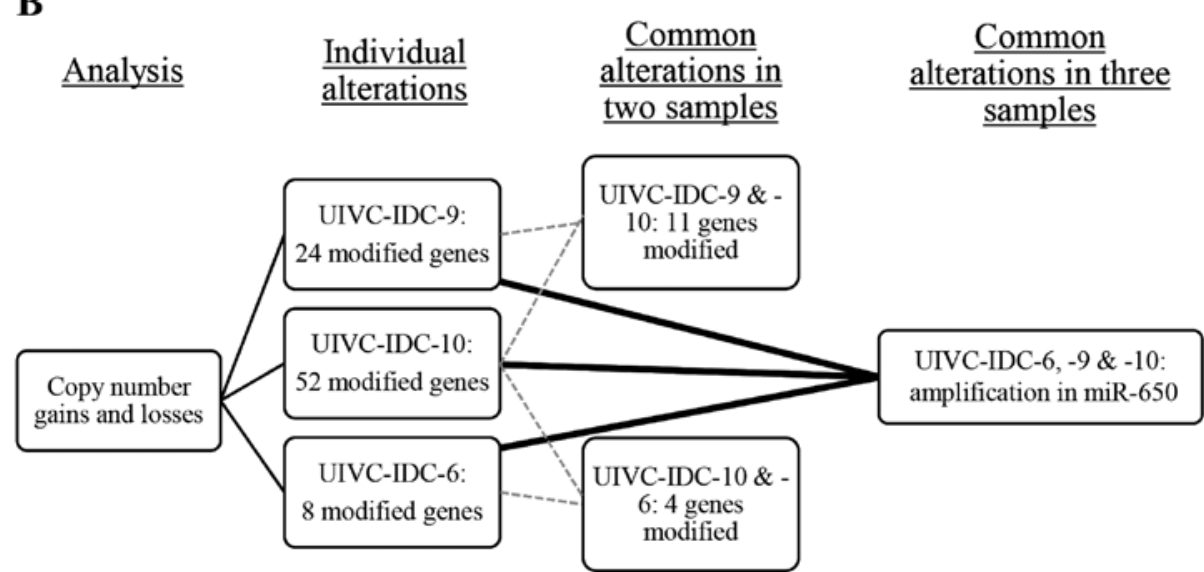

Figure 1. LOH and gain and losses present in breast cancer primary cultures of Mexican patients. (A) LOH alterations in individual and in common in two samples. There were no $\mathrm{LOH}$ alterations in common in the three samples analyzed. (B) Gains and losses alterations in individual, and common in two and three samples. Analysis performed with the microarray CytoScan HD and the software Chromosome Analysis Suite 3.0. The gain of the region 22q11.2 that encodes for miR-650 was present in all the samples analyzed.

blocking buffer [10\% goat serum (Sigma, ref. G9023-10ML), $0.2 \%$ Triton $\mathrm{X}-100$ and $1 \%$ BSA (bovine serum albumin, Sigma, ref. A1933), in PBS 1X] for $1 \mathrm{~h}$, after which, cells were stained with mouse monoclonal anti-E-cadherin antibody (1:100, 610181, BD Biosciences, San Jose, CA, USA) and with rabbit monoclonal anti-vimentin antibody-Alexa Fluor594 (1:2000, ab154207, Abcam, Cambridge, UK) overnight at $4^{\circ} \mathrm{C}$. Cells were then incubated with a goat anti-mouseIgG-FITC antibody for $30 \mathrm{~min}$ (1:50, F0257, Sigma-Aldrich Co.). Finally, nuclei were stained with DAPI (H1200, Vector Laboratories, Youngstown, OH, USA) for $25 \mathrm{~min}$. Cells were observed using a fluorescence microscope Olympus BX51 and images were acquired with a digital camera (Camedia C4040, Olympus, Segrate, Milan, Italy).

Invasion assay. Cells $\left(2 \times 10^{4}\right)$ were resuspended in $200 \mu \mathrm{l}$ DMEM/F12 medium and placed in the upper chamber of a Transwell [6.5-mm diameter, $8-\mu \mathrm{m}$ pore size (3422, Corning Inc., Corning, NY, USA)] covered with Matrigel (356237, Corning Inc.). Then, the Transwell was placed in a 24-well culture dish containing $1 \mathrm{ml}$ of DMEM/F12 medium supplemented with $10 \%$ fetal bovine serum (FBS) (16000-044, Gibco-Invitrogen). After $24 \mathrm{~h}$ of incubation at $37^{\circ} \mathrm{C}$, invasive cells were fixed with $4 \%$ paraformaldehyde and stained with Crystal-violet (Hycel Mexico, S.A. de C.V., ref. 541) and were observed using a microscope Motic AE31, images were

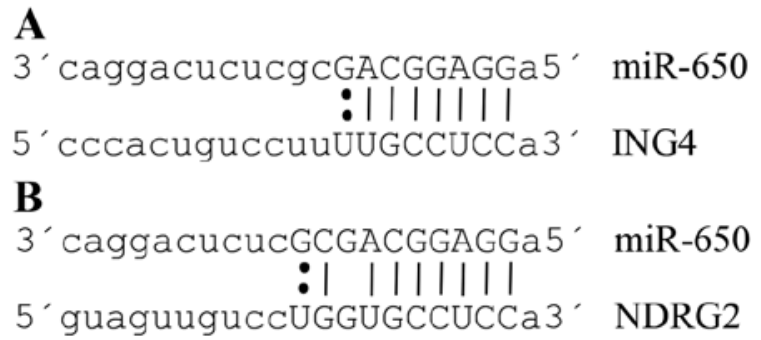

Figure 2. ING4 and NDRG2 are direct targets of miR-650. miR-650 targeting sequence found in ING4 (A) and NDRG2 (B) mRNAs. Both targeting sequences were found in MicroRNA.org database. Two black dots denote a $\mathrm{G}: \mathrm{U}$ mismatch wobble pairing.

acquired with a digital camera (Moticam 5.0 MP) both from Motic (China).

Flow cytometry. Cells $\left(3 \times 10^{5}\right)$ were blocked with PBS $1 \mathrm{x}$ supplemented with $50 \%$ FBS and incubated for 30 min with mouse anti human CD44-Phycoerythrin (555479) and CD24PE-Cy7 (561646) both from BD Biosciences. Cells were then incubated with 7AAD (559925, BD Biosciences). All acquisitions were performed in a FACS Canto II flow cytometer (Becton Dickinson, Frankin Lakes, NJ, USA). Finally, the analysis of flow cytometry data was performed on 7-AAD 


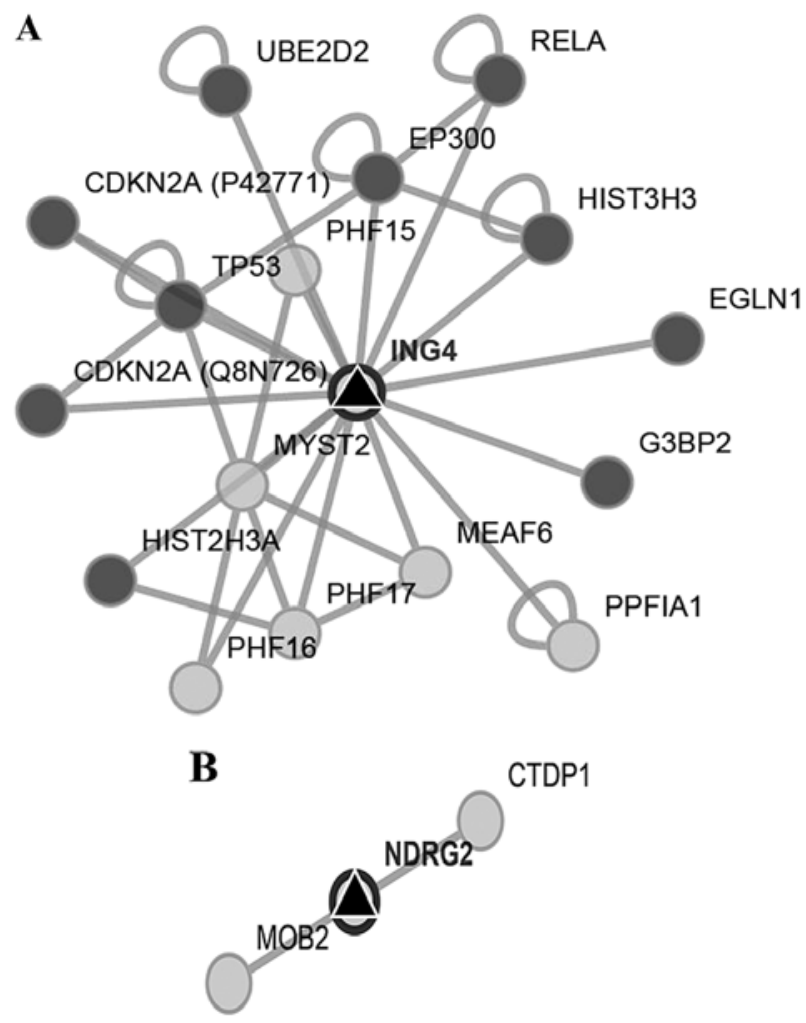

Figure 3. Interaction networks of ING4 and NDRG2. Interaction network of the proteins ING4 (A) and NDRG2 (B) created by the platform Pathway Linker. The proteins of interest are indicated with a black triangle, proteins directly interacting with ING4 and NDRG2 are shown in dark gray circles, in light gray circles are potential indirect interactions, the handle-shaped lines indicate self-regulatory proteins.

negative cells using FlowJo V10 software (Tree Star Inc., Ashland, OR, USA).

\section{Results}

Confirmation of the isolation of epithelial cells of breast tumors. We obtained three primary cultures of Mexican $\mathrm{BrC}$ patients and identified them as UIVC-IDC-6, -9 and -10 . Cultures were chosen in early passages $(<6)$ to reduce the risk of genetic changes induced during culture. All primary cultures were positive for epithelial markers PAN-CK, EpCAM and MUC-1 (data not shown). Expression of these markers is known to be maintained even after EMT.

Gain of miR-650 in the three BrC primary cultures. Using the microarray CytoScan HD and the software ChAS 3.0, we detected many chromosomal alterations (gains, losses and $\mathrm{LOH}$ ) per sample and in common in at least two samples. There were $103 \mathrm{LOH}$ in common between the sample UIVC-IDC-9 and UIVC-IDC-6, and 40 between the samples UIVC-IDC-10 and UIVC-IDC-6 (Fig. 1A). There were no LOH alterations in common in the three $\mathrm{BrC}$ samples. For gains and losses, UIVC-IDC-9 and UIVC-IDC-10 shared 11 alterations, and samples UIVC-IDC-10 and UIVC-IDC- 6 presented 4 common alterations. We found an amplification on the region 22q11.2 common to all samples (Fig. 1B), harboring the gene encoding miR-650 present in all the amplifications.
Table I. ING4 significant associations.

\begin{tabular}{ll} 
Cellular process or signaling pathway & P-value \\
\hline Cancer & $2.5 \mathrm{e}-10$ \\
Pancreatic cancer & $4.2 \mathrm{e}-09$ \\
Chronic myeloid leukemia & $4.4 \mathrm{e}-09$ \\
Cell cycle & $2.5 \mathrm{e}-08$ \\
Bladder cancer & $1.7 \mathrm{e}-07$ \\
Non-small cell carcinoma & $3.9 \mathrm{e}-07$ \\
P53 & $6.2 \mathrm{e}-07$ \\
Melanoma & $6.6 \mathrm{e}-07$ \\
Glioma & $7.0 \mathrm{e}-07$ \\
Prostate cancer & $1.6 \mathrm{e}-06$ \\
Renal cancer & 0.00015 \\
Systemic lupus erythematosus & 0.00017 \\
Small cell lung cancer & 0.00024 \\
Apoptosis & 0.00027 \\
Neurotrophin signaling pathway & 0.00052 \\
Huntington & 0.00066 \\
Wnt signaling & 0.00077 \\
MAPK signaling & 0.0022 \\
\hline
\end{tabular}

P-values $\geq 0.01$ denotes significant associations. WNT, Winglessrelated integration site; MAPK, mitogen-activated protein kinase.

ING4 and NDRG2, target genes of miR-650. We first searched for the interaction networks of miR-650 using the platform CytoScape, no relation with other miRNAs was found. We found that ING4 and NDRG2 genes were two potential miR-650 targets by reviewing preview reports and using the platforms Target Scan, miRDB, and MicroRNA. org (Fig. 2A and B). Then we used Pathway Linker platform to find interaction networks of these proteins observing an association with cell cycle and motility regulators (Fig. 3A and B). However, only for ING4 the platform found significant associations with signaling pathways and cellular processes (Table I).

Characterization of the EMT profile in BrC primary cultures. Several studies have shown that ING4 and NDRG2 suppress EMT (29-33). To determinate if the gain of the region 22q11.2 was associated with EMT, we analyzed cell morphology and the presence of EMT markers E-cadherin and vimentin by immunofluorescence. Noteworthy, all three primary cultures displayed a very homogeneous profile, the cells shared mesenchymal characteristics such as spindle-like morphology, negative expression of E-cadherin and high expression of vimentin (Fig. 4A). EMT identifies aggressive tumors because of the capacity of invasion of tumor cells. Transwell invasion assays confirmed that all samples were highly invasive (Fig. 4B). Moreover, the three primary isolates contained a high proportion of a population with a $\mathrm{BrC}$ stem cell-like phenotype CD44 $4^{\text {high }}$ CD2 $4^{\text {low }}$, UIVC-IDC- $6=76.8 \%$, UIVC-IDC-9 $=67.8 \%$ and UIVC-IDC-10 $=72.3 \%$ (Fig. 4C). The non-invasive $\mathrm{BrC}$ cell line MCF-7 was used as a negative 
A
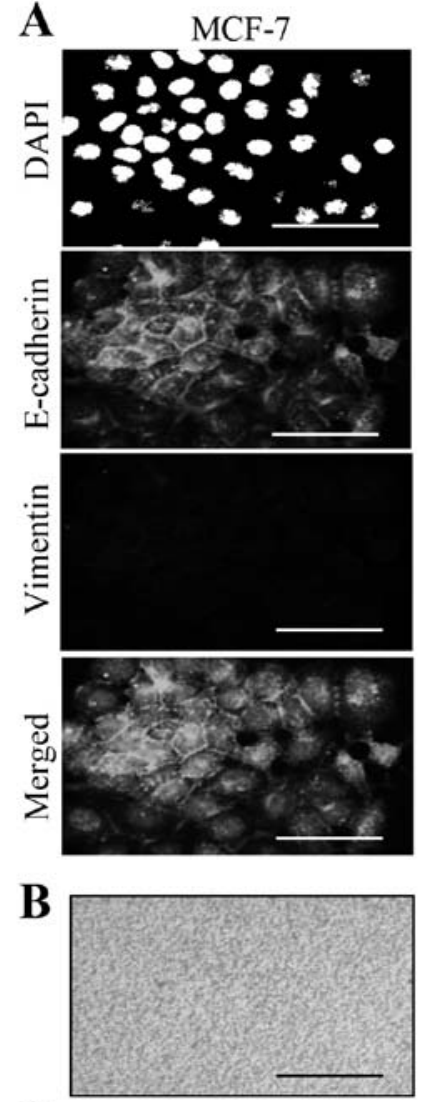

C

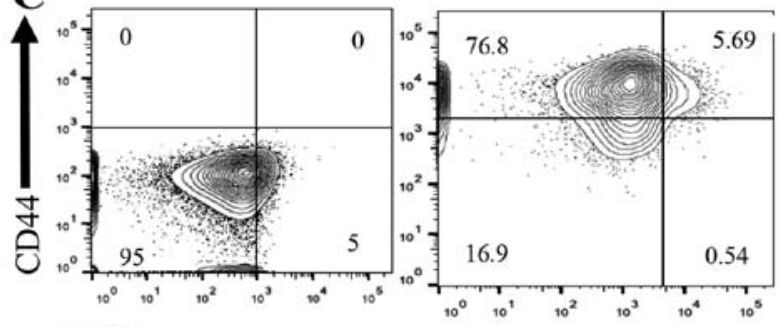

UIVC-IDC-6
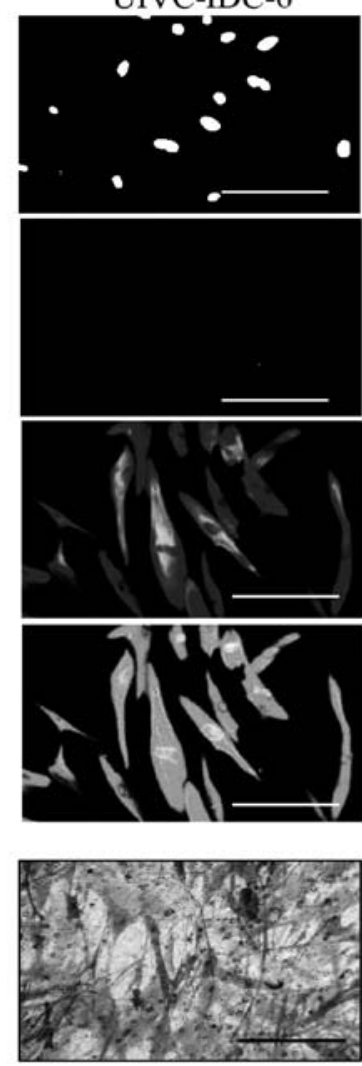

5.69

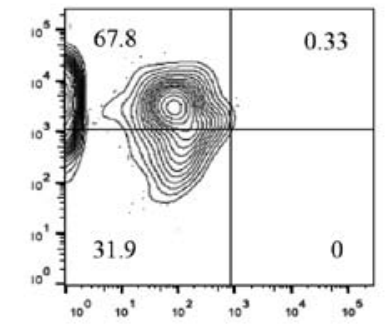

UIVC-IDC-9
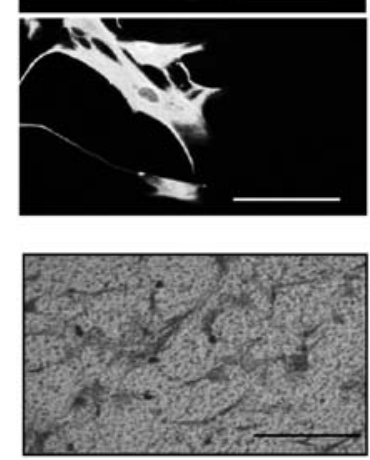

.33
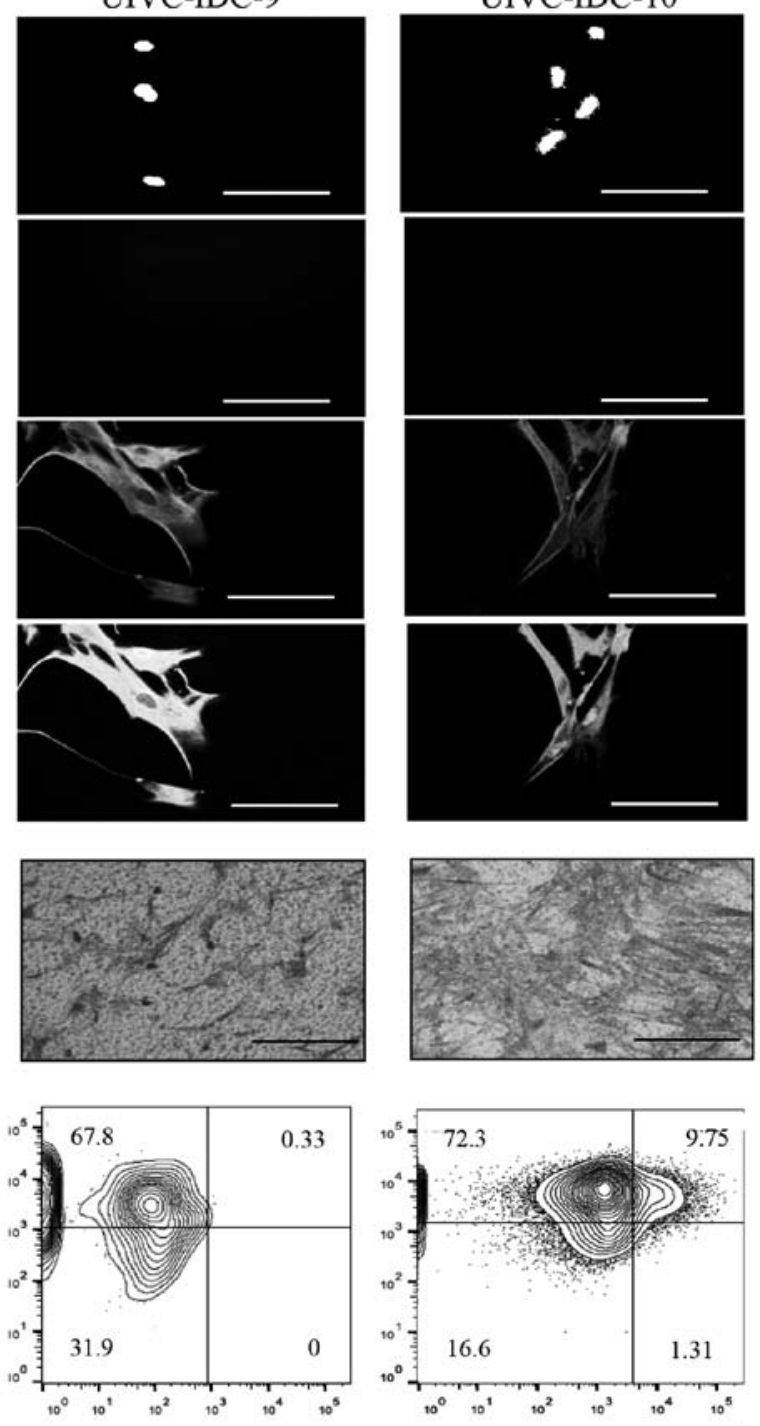

$\mathrm{CD} 24$

Figure 4. The human primary breast cancer cell isolates present aggressive features. (A) Immunofluorescence staining of the epithelial cell marker E-cadherin, the mesenchymal cell marker, the intermediary filament vimentin, and nuclei (DAPI) is shown as evidence of the epithelial to mesenchymal transition. (B) Invasion assay in Transwell chambers, invasive cells were stained with crystal violet and images were acquired with a digital camera. Bar scale indicates $100 \mu \mathrm{m}$. (C) Flow cytometry analysis based on the breast cancer stem cells phenotype CD $44^{+} \mathrm{CD} 24^{-/ / \text {low }}$.

control, and the highly aggressive BrC cell line MDA-MB-231 was used as positive control (data not shown). These results are in agreement with a model in which miR-650 amplification results in downregulation of ING4 and NDGR4 tumor suppressors and EMT (Fig. 5).

\section{Discussion}

We performed a cytogenetic analysis of three BrC primary cell cultures, using the CytoScan HD platform and ChAS 3.0 software of Affymetrix in order to search for genetic abnormalities associated with breast cancer $(\mathrm{BrC})$. We found a large number of gene copy number alterations, and LOH in each individual sample, but interestingly, we also observed a previously undescribed alteration in $\mathrm{BrC}$ studies that was common in the three primary isolates, pointing out a possible new highly represented feature in Mexican BrC patients.
Although, in vitro and in vivo evidence supports the association of miR-650 with cancer, to the best of our knowledge miR-650 has not been previously documented to be involved in BrC. Furthermore, increased expression of miR-650 often denotes cancers with aggressive features, which is also in support of our observations. Levels of miR-650 expression in glioma and hepatocellular carcinoma correlated with the grade of the tumor $(23,34)$. In gastric cancer the expression level of miR-650 was significantly associated with metastasis (25). Overexpression of miR-650 in gastric cancer cell lines increased the size and number of tumors in xenografted nude mice, and inhibition of miR-650 neutralized this effect (25). Other human cancers in which miR-650 has been implicated are prostate cancer, chronic lymphocytic leukemia, osteosarcoma and lung adenocarcinoma (21,35-37). miR-650 has been associated with downregulation of tumor suppressors ING4 and NDRG2 $(22,23,25,26)$. Because of 


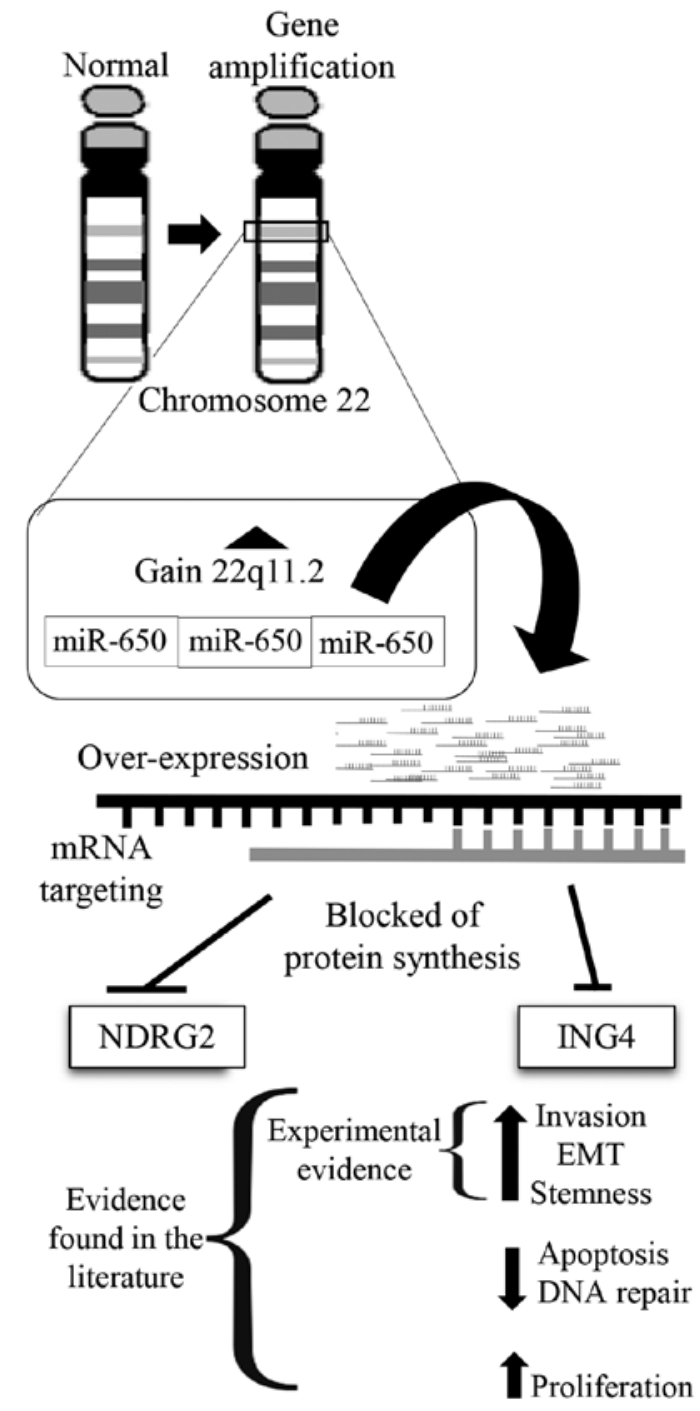

Figure 5. Model of miR-650 functions in breast cancer. A 22q11.2 amplification harboring the miR-650 coding sequence, leads to miR-650 overexpression and silencing of ING4 and NDRG2 tumor suppressor genes. Lack of expression of ING4 and NDRG2 contributes with the acquisition of aggressive features related to the epithelial to mesenchymal transition and to stemness.

these associations, it has been proposed that miR-650 is an oncomiR that regulates, apoptosis, cell cycle, DNA repair, EMT and metastasis $(22,23,34,35)$. Thus, miR-650 has also been proposed as a potential target for cancer treatment.

EMT is a normal de-differentiation process during embryogenesis. In the inner mass of the blastocyst, the pluripotent embryonic stem cells have epithelial characteristics and during gastrulation, the pluripotent epithelial epiblast ingress to form the primary mesoderm trough EMT $(38,39)$. In adults EMT has been associated with wound healing, tissue fibrosis and tissue regeneration, also named as Type 2 EMT (40). It is believed that in cancer, cellular changes associated with EMT facilitate cell invasion and metastasis (41). Tumor suppressors are important regulators of EMT, and there is evidence that ING4 and NDRG2 regulate EMT. Wang and collaborators found that ING4 inhibits migration of a thyroid cancer cell line by reversing the Wnt/ $\beta$-catenin pathway induced-EMT (30). Downregulation of ING4 has also been associated with progres- sion of lung cancer and head and neck carcinomas $(42,43)$, brain tumors and in some cases, ING4 expression also correlated with tumor grade (44). Using comparative genomic hybridization (CGH), Kim and colleagues found a deletion of the ING4 loci in 10-20\% of primary breast tumors and BrC cell lines (26). In a more mechanistic study, Bayron and collaborators found that ING4 inhibited NF- $\kappa$ B activity in the BrC cell line T47D (45). On the contrary, upregulation of ING4 in osteosarcoma cells induced cell apoptosis and suppressed cell invasion through downregulation of MMP-2, which also correlated with inhibition of NF- $\kappa \mathrm{B}$ activity (46). Other studies support that ING4 negatively regulates $\mathrm{NF}-\kappa \mathrm{B}$, and that ING4 downregulation associates with tumor progression and poor patient outcome (27,45-48).

There is also evidence that NDRG2 supports EMT-induced aggressive cancer features of different types of cancer cells, such as invasion and migration. Hong and collaborators found that epigenetic silencing of NDRG2 induced proliferation and invasion of primary colorectal cancer cells, and that this could be associated with advanced stages of the disease (49). Similarly, Lee and collaborators found that in patients with gallbladder carcinoma loss of NDRG2 expression was an independent predictor of decreased patient survival and was significantly associated with a more advanced tumor stage (32). In addition, loss of NDRG2 expression in gallbladder carcinoma cells resulted in enhanced proliferation, migration and invasiveness in vitro, and enhanced tumor growth and metastasis in mice (32). Using immunohistochemistry of tissues from patients with colon carcinoma, Kim and collaborators found that NDRG2 and E-cadherin were highly expressed in normal mucosa and in areas with well differentiated tumor cells, while areas of poorly differentiated carcinoma there was low to no expression of both proteins (50).

In the above study, NDRG2 knockdown induced downregulation of $C D H 1$ (encodes E-cadherin) promoter activity and upregulation of Snail-1, a master transcription factor regulator of EMT. In the aggressive BrC cell line MDA-MB-231, overexpression of NDRG2 results in downregulation of Snail-1 and upregulation of $C D H 1$ (33). TGF- $\beta$ is perhaps the most used inducer of EMT in in vitro studies, and Shen and collaborators showed that NDRG2 abrogates the TGF- $\beta$-induced EMT (31).

In another study in gallbladder carcinoma cells, loss of NDRG2 created an EMT positive feedback loop by increasing the expression of the tyrosine kinase receptor Axl, that regulated the expression of Slug, another master regulator of EMT (32). MDA-MB-231 and MCF-7 are highly metastatic and no-metastatic $\mathrm{BrC}$ cell lines, respectively, in which the metastatic potential correlates with the levels of NDRG2 (33). NDRG2 also inhibited NF- $\kappa \mathrm{B}$ signaling in MDA-MB-231 cells, together with the PMA-induction of the tumor-promoting enzyme cyclooxygenase 2 (COX-2) and one of the COX-2 most relevant pro-tumoral products, prostaglandin E2 (PGE2). NDRG2 strongly repressed phorbol 12-myristate 13-acetate (PMA)stimulated migration and invasion of MDA-MB-231 cells. On the other hand, siRNA-mediated knockdown of NDRG2 in MCF-7 cells resulted in increased COX-2 and NF- $\kappa \mathrm{B}$ activity after PMA activation, correlating with an increased capacity of cell migration and invasion (51). There is also evidence that NDRG2 overexpression reduces proliferation, migration and invasion of lung, bladder, and colorectal cancer cells $(28,52,53)$. 
In solid tumors, a scarce population with capacity of selfrenew has been described, this population seeds new tumors upon serial passages in mice and reconstitutes all types of tumor cells both in vivo and in culture. These cells are thought to be cancer stem cells (CSC) and are considered the most clinical relevant population because this may be the population that is responsible for metastases, resistance to chemotherapy and disease relapse (54-57). There is experimental evidence of a direct molecular link between EMT and stemness. In 2003, Mani et al demonstrated that the induction of EMT resulted in acquisition of both mesenchymal and stem characteristics, for instance a fibroblastoid morphology together with a $\mathrm{BrC}$ stem cell (BrCSC) phenotype CD $44^{\text {high }} \mathrm{CD} 24^{\text {low }}$ (9). Since EMT is a prerequisite for the invasion-metastasis cascade (58), evidence shows that metastatic CD $44^{\text {high }} \mathrm{CD} 24^{\text {low }} \mathrm{BrCSCs}$ strongly express the TGF- $\beta$-induced signature associated with EMT (59). Of clinical significance, Santisteban et al demonstrated that induction of EMT increased the density of BrCSCs, which correlated with high tumorigenicity in mice, and resistance to pharmacological and radiation treatment (60). Thus, there is an important association between EMT, CSCs, relapse and treatment failure (61-63). Although, there is no direct evidence linking expression of miR-650, ING4 and NDRG2 with CSCs, various evidence supports that high miR-650 and/ or low ING4 and NDRG2 correlates with advanced cancers and poor patient outcome $(22,25,33,43,48,53,64)$. Furthermore, NDRG2 has been found to downregulate CD24 expression in hepatocellular carcinoma cell lines and tissues and miR-650 has been found in microvesicles released by CD105 positive renal carcinoma stem cells $(65,66)$.

In this study, we found a common amplification in the 22 q11.2 band in primary isolates of three Mexican patients with $\mathrm{BrC}$. In all the cases this amplification included the region encoding miR-650, an oncomiRNA previously associated with invasive cancers, although never before described in BrC. Two of the most studied targets of miR-650 are tumor suppressors NDGR2 and ING4, which have been documented to negatively regulate EMT. Our data support a model in which miR-650 amplification results in NDGR2 and ING4 downregulation that then triggers EMT, acquisition of cancer stem cell markers and invasion. A limitation of this study is the small number of samples analyzed to have a better idea of how common this genetic lesion is in Mexican patients with BrC. Of note, our data also suggest that these patients harbor aggressive tumors. However, these tumors were classified with invasive ductal carcinoma, histological grade 2 and clinical stage II, considered of intermediate prognosis. In future studies, it is critical to follow up BrC patients with the $22 \mathrm{q} 11.2$ amplification.

\section{Acknowledgements}

This work was supported by CONACyT FONSEC SSA/IMSS/ ISSSTE project no. 233061 to Ezequiel M. Fuentes-Pananá and by Fondo de Apoyo a la Investigación, Hospital Infantil de México Federico Gómez (project number HIM-2014-053). N.A.E.-S. is a doctoral student from Programa de Doctorado en Ciencias Biomédicas, Universidad Nacional Autónoma de México (UNAM) and received fellowship 231663 from CONACYT. N.A.E.-S., also acknowledged the financial support provided by the Mexican Institute of Social Security (IMSS). M.C.S.-A. acknowledged the scholarship and financial support provided by Consejo Nacional de Ciencia y Tecnología (CONACyT \#576518). The authors are grateful to A.C. Velázquez-Wong and C. Jiménez Ramírez for technical assistance in arrays processing.

\section{References}

1. International Agency for Research on Cancer (IARC): Latest world cancer statistics, Global cancer burden rises to 14.1 million new cases in 2012: Marked increase in breast cancers must be addressed. Press Release 223: 2013. https://www. iarc.fr/en/media-centre/pr/2013/pdfs/pr223_E.pdf. Accessed December 12, 2013.

2. International Agency for Research on Cancer (IARC): GLOBOCAN: Estimated Cancer Incidence, Mortality and Prevalence Worldwide in 2012. 2012. http://globocan.iarc.fr/ Default.aspx.

3. Greaves M and Maley CC: Clonal evolution in cancer. Nature 481: 306-313, 2012.

4. Suzuki HI, Katsura A, Matsuyama H and Miyazono K: MicroRNA regulons in tumor microenvironment. Oncogene 34: 3085-3094, 2015.

5. Scheel C, Onder T, Karnoub A, Weinberg RA and Talmadge JE: Adaptation versus selection: The origins of metastatic behavior. Cancer Res 67: 11476-11479, discussion 11479-11480, 2007.

6. Thiery JP and Sleeman JP: Complex networks orchestrate epithelial-mesenchymal transitions. Nat Rev Mol Cell Biol 7: 131-142, 2006.

7. Kang Y and Massagué J: Epithelial-mesenchymal transitions: Twist in development and metastasis. Cell 118: 277-279, 2004.

8. Voulgari A and Pintzas A: Epithelial-mesenchymal transition in cancer metastasis: Mechanisms, markers and strategies to overcome drug resistance in the clinic. Biochim Biophys Acta 1796: 75-90, 2009.

9. Mani SA, Guo W, Liao MJ, Eaton EN, Ayyanan A, Zhou AY, Brooks M, Reinhard F, Zhang CC, Shipitsin M, et al: The epithelial-mesenchymal transition generates cells with properties of stem cells. Cell 133: 704-715, 2008.

10. Morel AP, Lièvre M, Thomas C, Hinkal G, Ansieau S and Puisieux A: Generation of breast cancer stem cells through epithelial-mesenchymal transition. PLoS One 3: e2888, 2008.

11. Scheel C, Eaton EN, Li SH, Chaffer CL, Reinhardt F, Kah KJ, Bell G, Guo W, Rubin J, Richardson AL, et al: Paracrine and autocrine signals induce and maintain mesenchymal and stem cell states in the breast. Cell 145: 926-940, 2011.

12. Beck B, Lapouge G, Rorive S, Drogat B, Desaedelaere K, Delafaille S, Dubois C, Salmon I, Willekens K, Marine JC, et al: Different levels of Twist1 regulate skin tumor initiation, stemness, and progression. Cell Stem Cell 16: 67-79, 2015.

13. Luo M, Brooks M and Wicha MS: Epithelial-mesenchymal plasticity of breast cancer stem cells: Implications for metastasis and therapeutic resistance. Curr Pharm Des 21: 1301-1310, 2015.

14. Medema JP: Cancer stem cells: The challenges ahead. Nat Cell Biol 15: 338-344, 2013.

15. Zhang B, Pan X, Cobb GP and Anderson TA: microRNAs as oncogenes and tumor suppressors. Dev Biol 302: 1-12, 2007.

16. Mongroo PS and Rustgi AK: The role of the miR-200 family in epithelial-mesenchymal transition. Cancer Biol Ther 10: 219-222, 2010.

17. Park SM, Gaur AB, Lengyel E and Peter ME: The miR-200 family determines the epithelial phenotype of cancer cells by targeting the E-cadherin repressors ZEB1 and ZEB2. Genes Dev 22: 894-907, 2008.

18. Comijn J, Berx G, Vermassen P, Verschueren K, van Grunsven L, Bruyneel E, Mareel M, Huylebroeck D and van Roy F: The twohanded $\mathrm{E}$ box binding zinc finger protein SIP1 downregulates E-cadherin and induces invasion. Mol Cell 7: 1267-1278, 2001.

19. Eger A, Aigner K, Sonderegger S, Dampier B, Oehler S, Schreiber M,Berx G, Cano A, Beug H and Foisner R: DeltaEF1 is a transcriptional repressor of E-cadherin and regulates epithelial plasticity in breast cancer cells. Oncogene 24: 2375-2385, 2005.

20. Howe EN, Cochrane DR and Richer JK: The miR-200 and miR-221/222 microRNA families: Opposing effects on epithelial identity. J Mammary Gland Biol Neoplasia 17: 65-77, 2012. 
21. Zuo ZH, Yu YP, Ding Y, Liu S, Martin A, Tseng G and Luo JH: Oncogenic activity of miR-650 in prostate cancer is mediated by suppression of CSR1 expression. Am J Pathol 185: 1991-1999, 2015.

22. Feng L, Xie Y, Zhang $\mathrm{H}$ and Wu Y: Down-regulation of NDRG2 gene expression in human colorectal cancer involves promoter methylation and microRNA-650. Biochem Biophys Res Commun 406: 534-538, 2011.

23. Zeng ZL, Li FJ, Gao F, Sun DS and Yao L: Upregulation of miR-650 is correlated with down-regulation of ING4 and progression of hepatocellular carcinoma. J Surg Oncol 107: 105-110, 2013.

24. Chan E, Patel R, Nallur S, Ratner E, Bacchiocchi A, Hoyt K, Szpakowski S, Godshalk S, Ariyan S, Sznol M, et al: MicroRNA signatures differentiate melanoma subtypes. Cell Cycle 10: $1845-1852,2011$

25. Zhang X, Zhu W, Zhang J, Huo S, Zhou L, Gu Z and Zhang M: MicroRNA-650 targets ING4 to promote gastric cancer tumorigenicity. Biochem Biophys Res Commun 395: 275-280, 2010.

26. Kim S, Chin K, Gray JW and Bishop JM: A screen for genes that suppress loss of contact inhibition: Identification of ING4 as a candidate tumor suppressor gene in human cancer. Proc Natl Acad Sci USA 101: 16251-16256, 2004.

27. Fang F, Luo LB, Tao YM, Wu F and Yang LY: Decreased expression of inhibitor of growth 4 correlated with poor prognosis of hepatocellular carcinoma. Cancer Epidemiol Biomarkers Prev 18: 409-416, 2009

28. Li R, Yu C, Jiang F, Gao L, Li J, Wang Y, Beckwith N, Yao L, Zhang $\mathrm{J}$ and $\mathrm{Wu} \mathrm{G}$ : Overexpression of N-Myc downstreamregulated gene 2 (NDRG2) regulates the proliferation and invasion of bladder cancer cells in vitro and in vivo. PLoS One 8: e76689, 2013.

29. Qu H, Yin H, Yan S, Tao M, Xie Y and Chen W: Inhibitor of growth 4 suppresses colorectal cancer growth and invasion by inducing G1 arrest, inhibiting tumor angiogenesis and reversing epithelial-mesenchymal transition. Oncol Rep 35: 2927-2935, 2016.

30. Wang CJ, Yang D and Luo YW: Recombinant ING4 suppresses the migration of SW579 thyroid cancer cells via epithelial to mesenchymal transition. Exp Ther Med 10: 603-607, 2015.

31. Shen L, Qu X, Ma Y, Zheng J, Chu D, Liu B, Li X, Wang M, $\mathrm{Xu} C$, Liu N, et al: Tumor suppressor NDRG2 tips the balance of oncogenic TGF- $\beta$ via EMT inhibition in colorectal cancer. Oncogenesis 3: e86, 2014.

32. Lee DG, Lee SH, Kim JS, Park J, Cho YL, Kim KS, Jo DY, Song IC, Kim N, Yun HJ, et al: Loss of NDRG2 promotes epithelial-mesenchymal transition of gallbladder carcinoma cells through MMP-19-mediated Slug expression. J Hepatol 63: $1429-1439,2015$

33. Kim MJ, Lim J, Yang Y, Lee MS and Lim JS: N-myc downstream-regulated gene 2 (NDRG2) suppresses the epithelial-mesenchymal transition (EMT) in breast cancer cells via STAT3/Snail signaling. Cancer Lett 354: 33-42, 2014.

34. Sun B, Pu B, Chu D, Chu X, Li W and Wei D: MicroRNA-650 expression in glioma is associated with prognosis of patients. $\mathrm{J}$ Neurooncol 115: 375-380, 2013.

35. Mraz M, Dolezalova D, Plevova K, Stano Kozubik K, Mayerova V, Cerna K, Musilova K, Tichy B, Pavlova S, Borsky M, et al: MicroRNA-650 expression is influenced by immunoglobulin gene rearrangement and affects the biology of chronic lymphocytic leukemia. Blood 119: 2110-2113, 2012.

36. Yun JH, Moon S, Lee HS, Hwang MY, Kim YJ, Yu HY, Kim Y, Han BG, Kim BJ and Kim JM: MicroRNA-650 in a copy number-variable region regulates the production of interleukin 6 in human osteosarcoma cells. Oncol Lett 10: 2603-2609, 2015.

37. Huang JY, Cui SY, Chen YT, Song HZ, Huang GC, Feng B, Sun M, De W, Wang R and Chen LB: MicroRNA-650 was a prognostic factor in human lung adenocarcinoma and confers the docetaxel chemoresistance of lung adenocarcinoma cells via regulating Bcl-2/Bax expression. PLoS One 8: e72615, 2013.

38. Acloque $\mathrm{H}$, Adams MS, Fishwick K, Bronner-Fraser M and Nieto MA: Epithelial-mesenchymal transitions: The importance of changing cell state in development and disease. J Clin Invest 119: 1438-1449, 2009.

39. Eastham AM, Spencer H, Soncin F, Ritson S, Merry CL, Stern PL and Ward CM: Epithelial-mesenchymal transition events during human embryonic stem cell differentiation. Cancer Res 67: 11254-11262, 2007.
40. Kalluri R and Weinberg RA: The basics of epithelial-mesenchymal transition. J Clin Invest 119: 1420-1428, 2009.

41. Steinestel K, Eder S, Schrader AJ and Steinestel J: Clinical significance of epithelial-mesenchymal transition. Clin Transl Med 3: 17, 2014.

42. Gunduz M, Nagatsuka H, Demircan K, Gunduz E, Cengiz B, Ouchida M, Tsujigiwa H, Yamachika E, Fukushima K, Beder L, et al: Frequent deletion and down-regulation of ING4, a candidate tumor suppressor gene at $12 \mathrm{p} 13$, in head and neck squamous cell carcinomas. Gene 356: 109-117, 2005.

43. Wang QS, Li M, Zhang LY, Jin Y, Tong DD, Yu Y, Bai J, Huang Q, Liu FL, Liu A, et al: Down-regulation of ING4 is associated with initiation and progression of lung cancer. Histopathology 57: 271-281, 2010.

44. Garkavtsev I, Kozin SV, Chernova O, Xu L, Winkler F, Brown E, Barnett GH and Jain RK: The candidate tumour suppressor protein ING4 regulates brain tumour growth and angiogenesis. Nature 428: 328-332, 2004.

45. Byron SA, Min E, Thal TS, Hostetter G, Watanabe AT, Azorsa DO, Little TH, Tapia C and Kim S: Negative regulation of NF- $\kappa \mathrm{B}$ by the ING4 tumor suppressor in breast cancer. PLoS One 7: e46823, 2012.

46. Li M, Zhu Y, Zhang H, Li L, He P, Xia H, Zhang Y and Mao C: Delivery of inhibitor of growth 4 (ING4) gene significantly inhibits proliferation and invasion and promotes apoptosis of human osteosarcoma cells. Sci Rep 4: 7380, 2014.

47. Shen JC, Unoki M, Ythier D, Duperray A, Varticovski L, Kumamoto K, Pedeux R and Harris CC: Inhibitor of growth 4 suppresses cell spreading and cell migration by interacting with a novel binding partner, liprin alpha1. Cancer Res 67: 2552-2558, 2007.

48. Li J and Li G: Cell cycle regulator ING4 is a suppressor of melanoma angiogenesis that is regulated by the metastasis suppressor BRMS1. Cancer Res 70: 10445-10453, 2010.

49. Hong SN, Kim SJ, Kim ER, Chang DK and Kim YH: Epigenetic silencing of NDRG2 promotes colorectal cancer proliferation and invasion. J Gastroenterol Hepatol 31: 164-171, 2016.

50. Kim YJ, Kang HB, Yim HS, Kim JH and Kim JW: NDRG2 positively regulates E-cadherin expression and prolongs overall survival in colon cancer patients. Oncol Rep 30: 1890-1898, 2013.

51. Kim MJ, Kim HS, Lee SH, Yang Y, Lee MS and Lim JS: NDRG2 controls COX-2/PGE(2)-mediated breast cancer cell migration and invasion. Mol Cells 37: 759-765, 2014.

52. Faraji SN, Mojtahedi Z, Ghalamfarsa G and Takhshid MA: $\mathrm{N}$-myc downstream regulated gene 2 overexpression reduces matrix metalloproteinase- 2 and -9 activities and cell invasion of A549 lung cancer cell line in vitro. Iran J Basic Med Sci 18: 773-779, 2015.

53. Golestan A, Mojtahedi Z, Ghalamfarsa G, Hamidinia M and Takhshid MAP: The effects of NDRG2 overexpression on cell proliferation and invasiveness of SW48 colorectal cancer cell line. Iran J Med Sci 40: 430-439, 2015.

54. Kreso A and Dick JE: Evolution of the cancer stem cell model. Cell Stem Cell 14: 275-291, 2014.

55. Al-Hajj M, Wicha MS, Benito-Hernandez A, Morrison SJ and Clarke MF: Prospective identification of tumorigenic breast cancer cells. Proc Natl Acad Sci USA 100: 3983-3988, 2003.

56. O'Brien CA, Pollett A, Gallinger S and Dick JE: A human colon cancer cell capable of initiating tumour growth in immunodeficient mice. Nature 445: 106-110, 2007.

57. Singh SK, Hawkins C, Clarke ID, Squire JA, Bayani J, Hide T, Henkelman RM, Cusimano MD and Dirks PB: Identification of human brain tumour initiating cells. Nature 432: 396-401, 2004.

58. Nieto MA: Epithelial-mesenchymal transitions in development and disease: Old views and new perspectives. Int J Dev Biol 53: 1541-1547, 2009.

59. Shipitsin M, Campbell LL, Argani P, Weremowicz S, BloushtainQimron N, Yao J, Nikolskaya T, Serebryiskaya T, Beroukhim R, $\mathrm{Hu} \mathrm{M}$, et al: Molecular definition of breast tumor heterogeneity. Cancer Cell 11: 259-273, 2007.

60. Santisteban M, Reiman JM, Asiedu MK, Behrens MD, Nassar A, Kalli KR, Haluska P, Ingle JN, Hartmann LC, Manjili MH, et al: Immune-induced epithelial to mesenchymal transition in vivo generates breast cancer stem cells. Cancer Res 69: 2887-2895, 2009.

61. Dave B, Mittal V, Tan NM and Chang JC: Epithelial-mesenchymal transition, cancer stem cells and treatment resistance. Breast Cancer Res 14: 202, 2012. 
62. Davis FM, Stewart TA, Thompson EW and Monteith GR Targeting EMT in cancer: Opportunities for pharmacological intervention. Trends Pharmacol Sci 35: 479-488, 2014.

63. Krause M, Dubrovska A, Linge A and Baumann M: Cancer stem cells: Radioresistance, prediction of radiotherapy outcome and specific targets for combined treatments. Adv Drug Deliv Rev: Feb 12, 2016 (Epub ahead of print).

64. Kloten V, Schlensog M, Eschenbruch J, Gasthaus J, Tiedemann J, Mijnes J, Heide T, Braunschweig T, Knüchel R and Dahl E: Abundant NDRG2 expression is associated with aggressiveness and unfavorable patients' outcome in basal-like breast cancer. PLoS One 11: e0159073, 2016.
65. Zheng J, Li Y, Yang J, Liu Q, Shi M, Zhang R, Shi H, Ren Q, Ma J, Guo $\mathrm{H}$, et al: NDRG2 inhibits hepatocellular carcinoma adhesion, migration and invasion by regulating CD24 expression. BMC Cancer 11: 251-259, 1-9, 2011.

66. Grange C, Tapparo M, Collino F, Vitillo L, Damasco C, Deregibus MC, Tetta C, Bussolati B and Camussi G: Microvesicles released from human renal cancer stem cells stimulate angiogenesis and formation of lung premetastatic niche. Cancer Res 71: 5346-5356, 2011 